\title{
Production of porous Ni-Ti alloy and test of its biocompatibility under in-vivo conditions
}

\author{
Ali Kaya Gur ${ }^{1}$, Nuri Orhan ${ }^{1}$, Emine Unsaldı², Ali Said Durmuş², Neriman Çolakoğlu \\ ${ }^{1}$ Department of Metallurgy Education, Technical Education Faculty, Firat University, Elazig, Turkey; \\ ${ }^{2}$ Department of Surgery, Faculty of Veterinary, Firat University, Elazig, Turkey; \\ ${ }^{3}$ Histology and Embryology Department, Medical Faculty, Firat University, Elazig, Turkey. \\ Email: akgur@firat.edu.tr; norhan@firat.edu.tr; eunsaldi@firat.edu.tr; asdurmus@,firat.edu.tr; ncolakoglu@firat.edu.tr
}

Received 18 August 2010; revised 15 September 2010; accepted 19 September 2010

\begin{abstract}
Biomaterials have been out of commonly used materials in biomedical applications in recent years. Today among the mostly-used biocompatible metals are especially Ni-Ti alloys. For conducting this study, having extensive usage area in biomedical applications, Ni and Ti materials were utilized for an alloy production. Following being mixed using a suitable mixer at $49 \mathrm{Ni} / 51 \mathrm{Ti} \% \mathrm{wt}$., the alloy was exposed to cold pressure of $200 \mathrm{MPa}$ and sintered in a mold. In addition, the material gained porosity appearance thanks to usage of the synthesized (SHS) method and then the final shape of the specimen was taken using the method of wire electro erosion discharge machining (WEDM). Afterwards, the specimen was subjected to the biocompatibility test in in-vivo environment by means of on a 3-year-old female dog.
\end{abstract}

Keywords: Biomaterials; NiTi; Igntion; Implant; In-Vivo

\section{INTRODUCTION}

Biomaterials refer to materials which have ever-increasing importance and application areas in every passing day and are biocompatible, safe and effective, and also are either natural or artificial origin as well as improvement, increase or substitute for the organ, tissue or body functions [1]. Biomaterials science, one of the disciplines having had great progresses, has exhibited intensive efforts in developing new materials with capability of adjusting to biological systems when interacting with the biomedical systems. Used in fulfilling or supporting the functions of the living tissues belonging to the human body, biomaterials are either natural or synthetic materials in contact with body fluids (e.g. blood) permanently or at certain intervals. For this reason, the fact that the material to be implanted to the body fulfills partially or completely the function of the replaced organ in compliance with the body led to increase importance of biomaterials and expand their field of study [2].

Because of not fulfilling their functions caused from various reasons like disease, accidents and old age, some organs such as kneecap joints, femur, femur head and vertebrae are replaced with prosthetic materials, needed to be used at a certain period of time or lifelong in human body. These prosthetic materials have been studied by orthopedists $[3,4]$. Before being used on the body, biocompatible materials are compared with mechanical properties of that body part in terms of biomaterials' raw material. Compatibility between the problematic area and the implant to be used is a must. [5].

The materials used as the biomaterial must be strong, economical and compatible to human body. Depending on disabilities and various losses of organs, different materials are used in living organisms. For example, used as a biomaterial, a synthetic material needs not to affect the life system in any way in contact with the living tissue [6].

Metals and their alloys bear excellent mechanical properties thanks to their crystal structure and superior metallic bindings and in return have a great significance in field of biomaterials. They are utilized in various fields such as maxillofacial surgery, dental implants, and cardiovascular surgery as well as joint prostheses and bone replacement materials in orthopedic applications. In this respect, among the mostly emphasized issues related to biomaterial, are the resistance strength, the fatigue, the surface corrosion, and the allergic reaction properties to tissues and the biological compatibility [7].

In orthopedic applications titanium is one of biomaterial utilized material by courtesy of its properties like being inert, light-weight, and the ease to produce small sized specimens besides having the nontoxic structure, 
the antimagnetization, having better mechanical properties, high biocompatibility, corrosion resistance, and an elasticity module closer to that of bone [8]. NiTi alloys have the capability of regain their initial shape upon being heated. This capability is accepted as the shape memory property [3]. Dental bridges, vascular connections within the skull, muscles for artificial hearts, and orthopedic prostheses out of biomaterial applications are benefited from this shape memory property. Because of its biocompatibility to human body, the porous structure created in the Ni-Ti alloys with shape memory property has had an important application area in biomedical applications. In case of surgical implantation of hard tissues, artificial usage of the Ni-Ti alloy on human body is in question [9].

"NiTi" refers to the alloy composed of Nickel and Titanium (49Ni/51Ti\%) and showing the shape memory property depending on temperature following occurrence of deformation. The alloy has congruent compound structure at $630^{\circ} \mathrm{C}$ by $49 / 51 \% \mathrm{Ni}$ ratio and turns to liquid phase at $1310^{\circ} \mathrm{C}[1]$ by same ratios. Comparison with other known metallic materials of today shows that one of leading alternative material to be used replacing with natural bone is porous shape memory NiTi alloy $[10,11]$. Many different techniques are utilized in production of the NiTi alloy, but the production method with powder metallurgy out of these techniques comes into prominence due to its favorable characteristics; for example this method enables easy production for complex-shaped parts, has controllable initial porosity ratio, lack of machining after production, display non-occurrence of segregations unlike the products obtained by casting method [12].

However, during sintering carried out at higher sintering temperatures it is possible to observe anisotropic changes similar to those occurred in casting method. Accordingly, it is a necessity for sintering processing, conducted in order to increase the amount of porosity, to be performed in a controlled manner and at lower temperatures; otherwise, formation of dimensional changes is possible. The fact that NiTi based smart materials with shape memory are benefited in biomedical areas requires a porous structure derivation, but difficulties encountered in production of porous NiTi alloy restrict the researches [13]. In terms of biomedical applications, other important matters are to be capable of controlling the amount of porosity during production, to obtain the controlled channel widths, and produce more porous materials in addition to identify porosity and channel directions. [14].

For this study, a porous Ni-Ti alloy was produced and its usability as an implant material was tested in in-vivo environment.

\section{EXPERIMENTAL MATERIALS AND METHODS}

\subsection{Production of Ni-Ti Alloy}

In this study, $\mathrm{Ni}$ and $\mathrm{Ti}$ powders of which chemical compositions are illustrated in Table $\mathbf{1}$ were used. The high purity of the powders used in the study ensures assurance in terms of biomedical applications and Ti's having lower specific gravity will make the implant to be produced lighter.

Illustrated in Figure 1, Ni-Ti phase diagram is used for calculation of alloy ratios of the experiment specimens. Creating congruent compound structure at $630^{\circ} \mathrm{C}$ by $49 / 51 \% \mathrm{Ni}$ ratio, the alloy passes to liquid phase at $1310^{\circ} \mathrm{C}[1]$ by same ratios.

$\mathrm{Ni}$ and Ti powders were set after having been weighed at $49 / 51 \% \mathrm{Ni}$ ratios on a Scaltec brand scale with $10^{-5}$ sensitivity. Following the weighing process, using an apparatus designed and produced for the mixture process the powders were mixed at 1500 circulation/min for 20 minutes till obtaining a homogeneous mixture. Figure 2 illustrates the apparatus used for mixture process. The mixed powders were exposed to cold pressure of 200 $\mathrm{MPa}$ in a custom-made mold in Figure 3. Figure 4 illustrates the digital image of the compacted $\mathrm{Ni}-\mathrm{Ti}$ specimen.

The pressed specimens were sintered at $250^{\circ} \mathrm{C}$ for 30 minutes using a furnace oven with $2^{\circ} \mathrm{C}$ temperature sensitivity. Schematic view of the oven is presented in Figure 5.

In performing the combustion process after sintering, one direction of the specimens was exposed to the current. The combustion in specimens, to which current was applied, continued to increase until the temperature reached to the ignition point on the initial surface and then continued throughout the specimen perpendicular to the ignition point. The combustion process resulted in the following exothermic reaction $[11,15]$ :

Table 1. The chemical compositions of Ni and Ti powders.

\begin{tabular}{cccccc}
\hline Materials & Purity (\%) & Powder Dimension $(\boldsymbol{\mu m})$ & Melting Degree $\left({ }^{\circ} \mathrm{C}\right)$ & Specific Gravity $\left(\mathbf{g r} / \mathbf{c m}^{3}\right)$ & Alloys Ratio $(\% \mathbf{w t})$ \\
\hline $\mathbf{T i}$ & 98,0 & $<150$ & 1680 & 4,5 & 49 \\
$\mathbf{N i}$ & 99,5 & 10 & 1453 & 8,9 & 51 \\
\hline
\end{tabular}




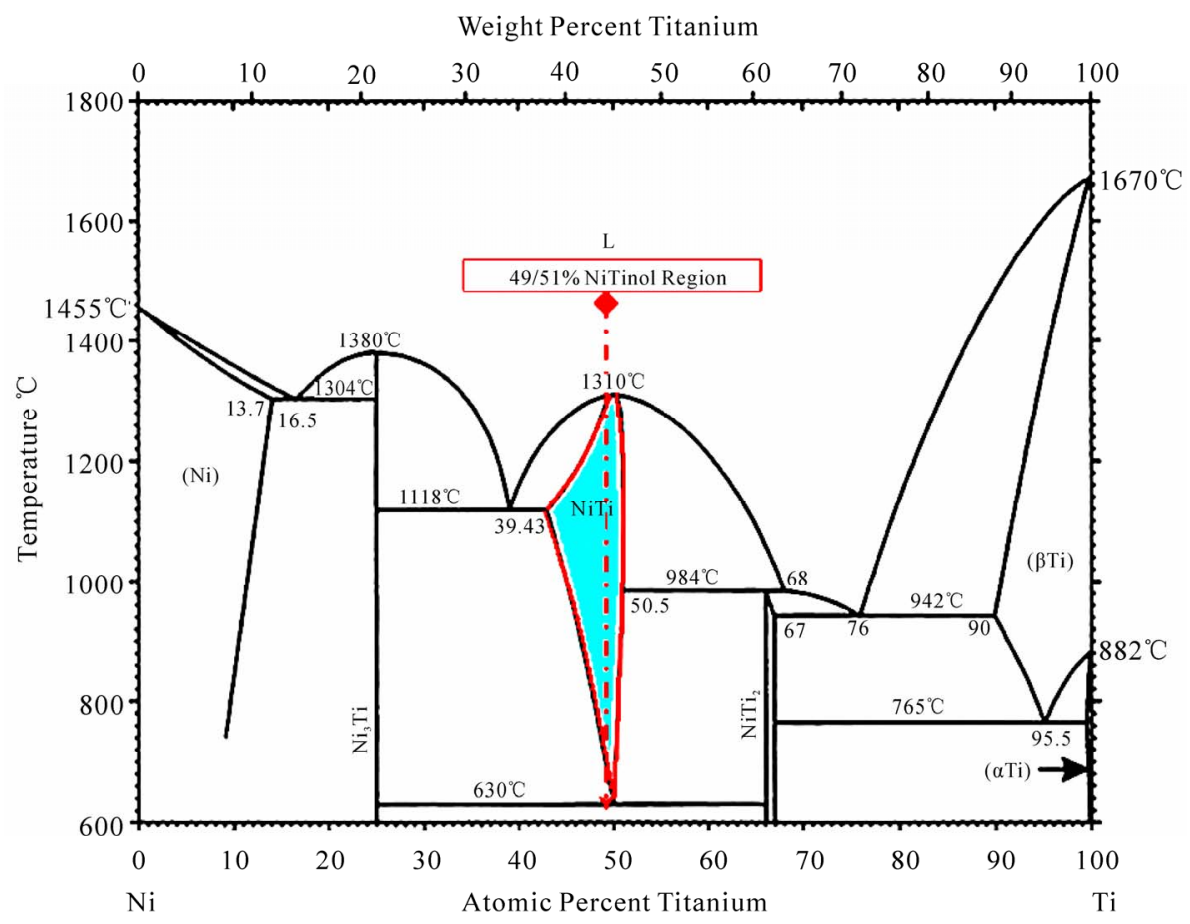

Figure 1. Ni-Ti phase diagram.



Figure 2. The schematic illustration of apparatus mixing of NiTi powders.

$$
\mathrm{Ni}+\mathrm{Ti} \rightarrow \mathrm{NiTi}+67 \mathrm{~kJ} / \mathrm{mol},
$$

After the first combustion, the combustion process continues to occur by itself on a regular basis in the

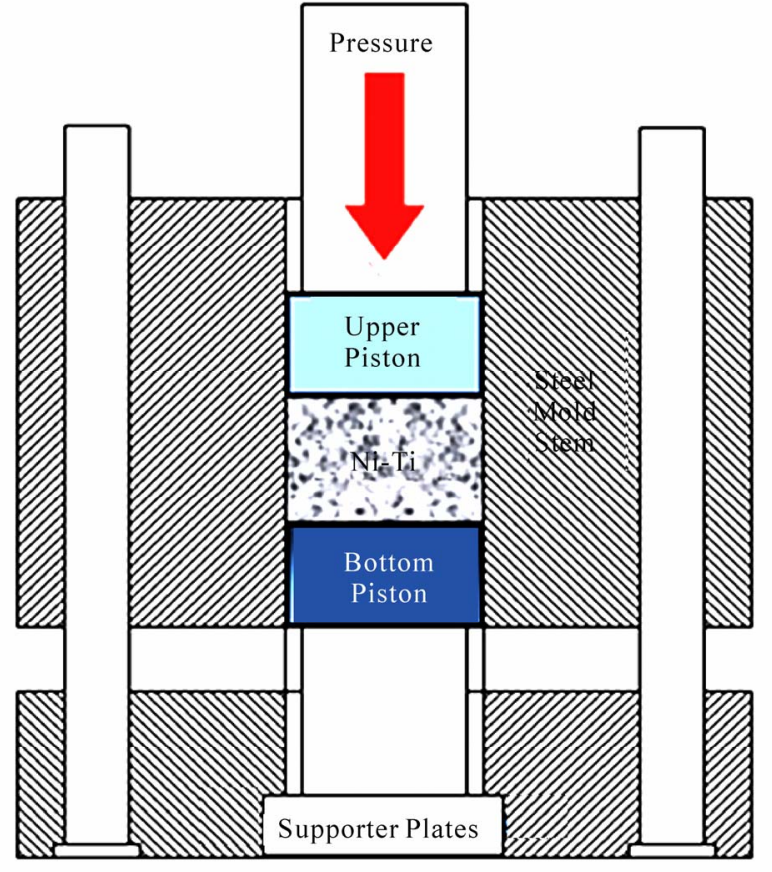

Figure 3. A Custom-made mold at compacted of the powders Ni-Ti.

same direction as the initial one. Throughout the specimen to which the ignition was applied, the combustion continued in the same direction and ratio. Figure 6 illustrates schematic view of porosity and channel formation 


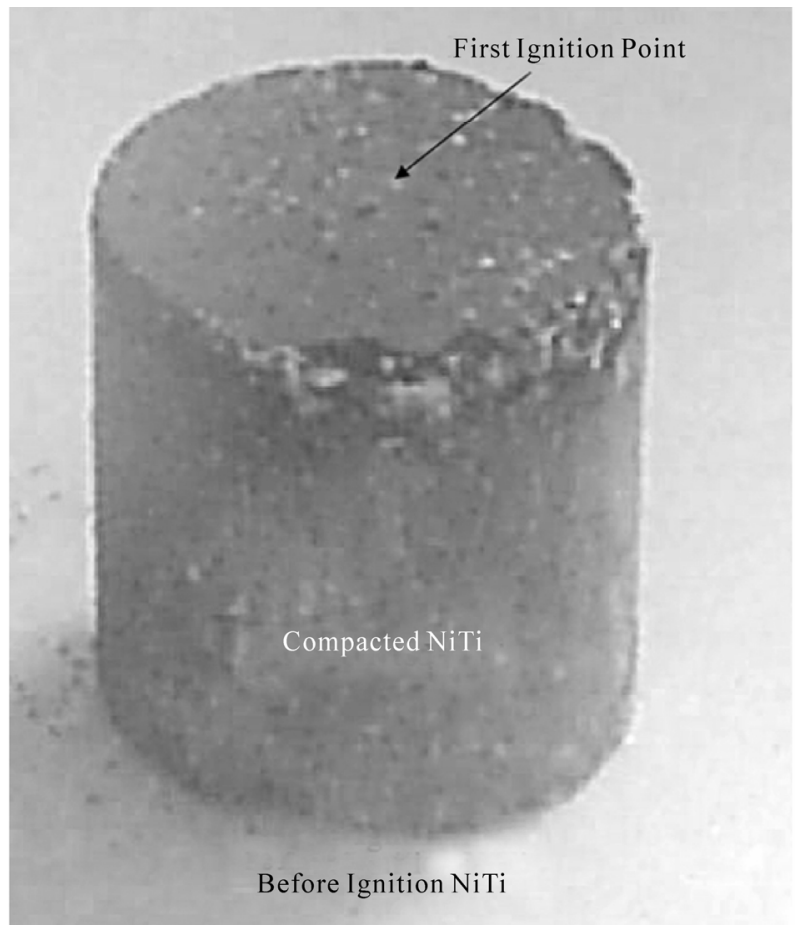

Figure 4. The digital picture of the compacted Ni-Ti specimen. in the specimen to which ignition was applied.

The side and top views of the digital images of the Ni-Ti powders after the ignition are seen in Figure 7. The ignition occurred from point I to II without interruption. As seen after the combustion process, proceeding direction of the channels is as parallel to each other and from the center to outward.

Illustrated in Figure 8, the specimen was processed at the Fine Sodick A320D - EX21 brand WEDM workbench and after having been processed, it was transformed into the status in Figure 8. As seen in Figure 8, the channels proceeded longitudinal and deeply in the specimen.

In order to determine the alloy ratios of the produced alloy, the surface of the material was polished and it was etched with $10 \% \mathrm{HF}, 5 \% \mathrm{HNO}_{3}$ and $\mathrm{H}_{2} \mathrm{O}$ etchant. After these process, the images and regional alloy values were taken using scanning electron microscope (SEM) and energy dispersive spectrometer (EDS), respectively. The results of the SEM-EDS values of the produced specimen are presented in Figure 9. Upon analysis of the EDS values and comparison of elementar percentages with the ones in the literature $[11,12]$, it is seen that the

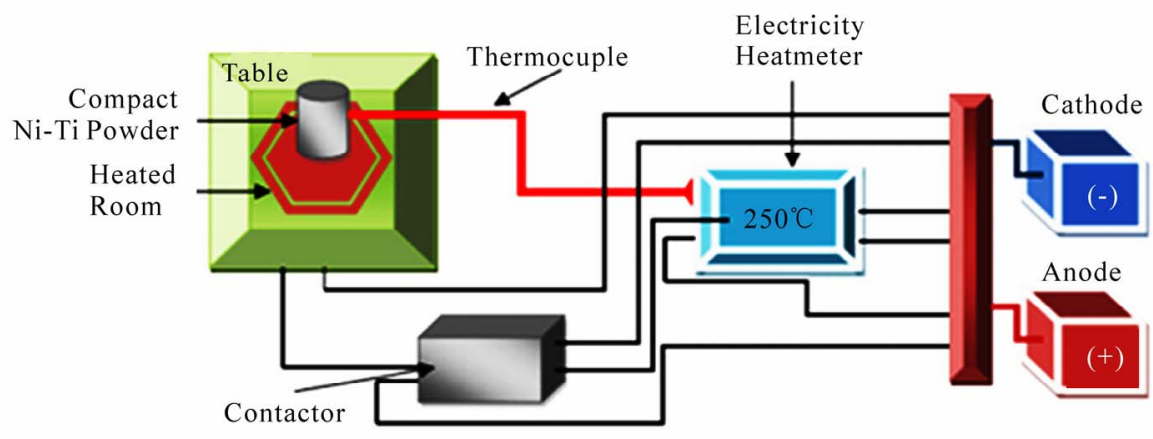

Figure 5. The schematic illustration at furnace temperature of Ni-Ti powders.

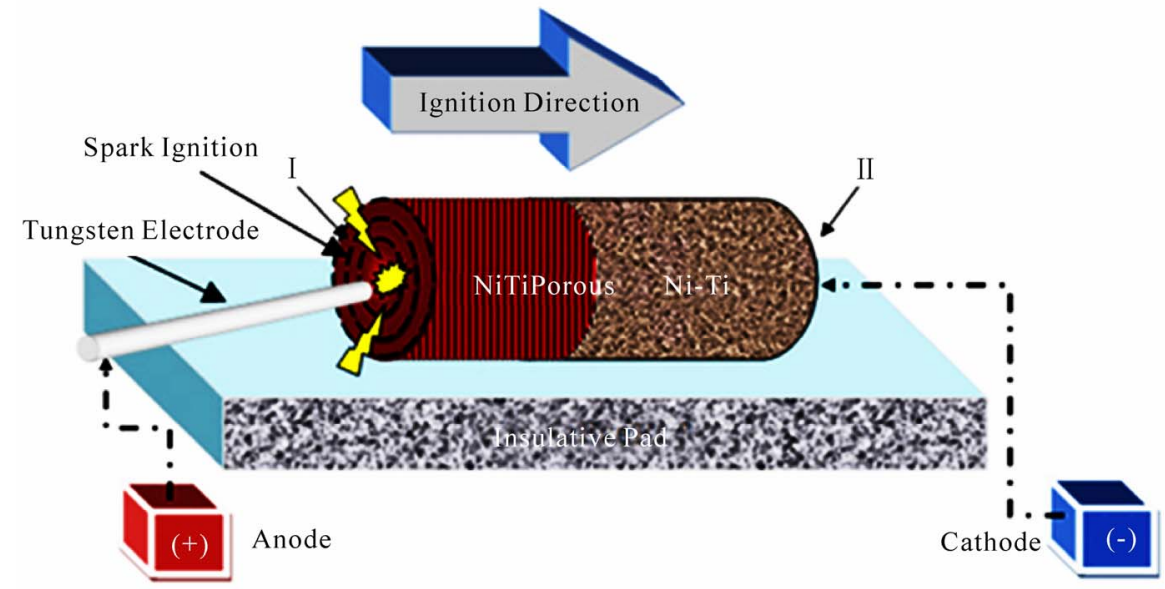

Figure 6. The specimen of ignition applied is seen schematically. 


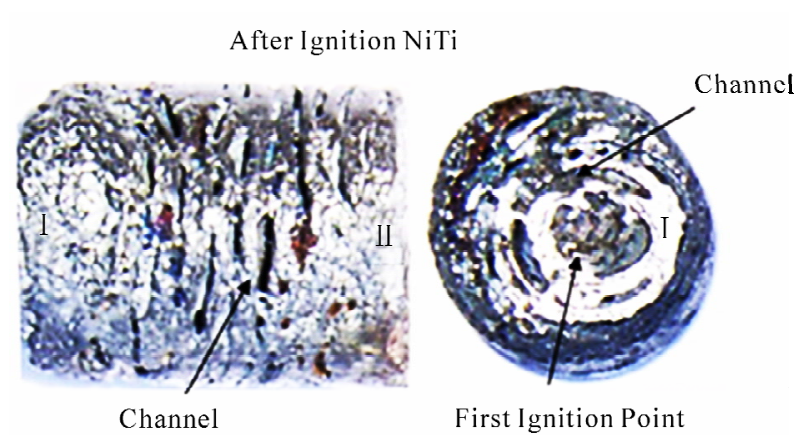

Figure 7. The digital pictures after the ignition of NiTi.

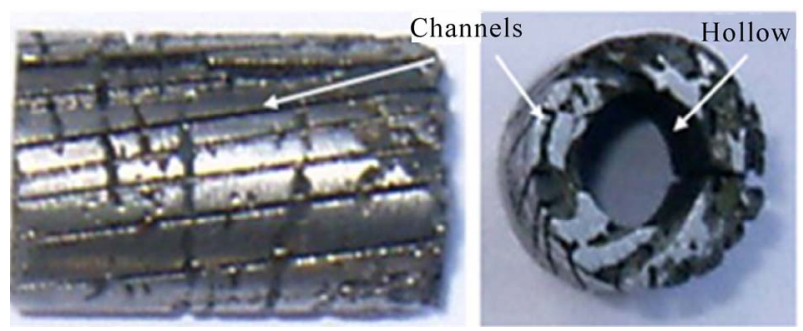

Figure 8. The digital pictures after the WEDM of NiTi.

produced specimen perfectly matches with the definition of the mentioned Ni-Ti alloy.

\subsection{Surgical Operations}

The biocompatibility test of the produced implant under in-vivo conditions was performed using a three-year-old healthy female dog. The experimental animal used in the study was cared and feed by the European Convention for the Protection of Vertebrate Animals used for Experimental and other Specific Purpose of 1996. Experiment was conducted in the Animal Hospital of Veterinary Faculty of the Firat University in Turkey in accordance with general guidelines.

Anesthesia was performed with intramuscular Ketalar, (Ketamin hydrochlorur, $50 \mathrm{mg} / \mathrm{ml}$ Davis, United Kingdom) injection at $15 \mathrm{mg} / \mathrm{kg}$ dose 10 minutes after intramuscular Rompun (Xylazine hydrochloride $23.32 \mathrm{mg} /$ $\mathrm{ml}$, Bayer, Leverkusen/Germany) injection at $3.5 \mathrm{mg} / 10$ $\mathrm{kg}$ dose.

Both of proximal tibias of the dogs were selected for the application, skin incision was performed on the proximal medial surface of the tibia on the same line as incision of subcutaneous fascia. A hole of $100 \mathrm{~mm}$ in diameter and $18 \mathrm{~mm}$ in depth was drilled at the proximal metaphysic of the revealed tibia. Figure 10 schematically illustrates this process. After the produced implant was placed in this opened hole, the subcutaneous fascia and the skin were closed with $2 / 0$ number chromic catgut, and 0 number silk thread, respectively.

Two-month clinical examination was made on the dog and at the end of this duration, the dog was euthanized
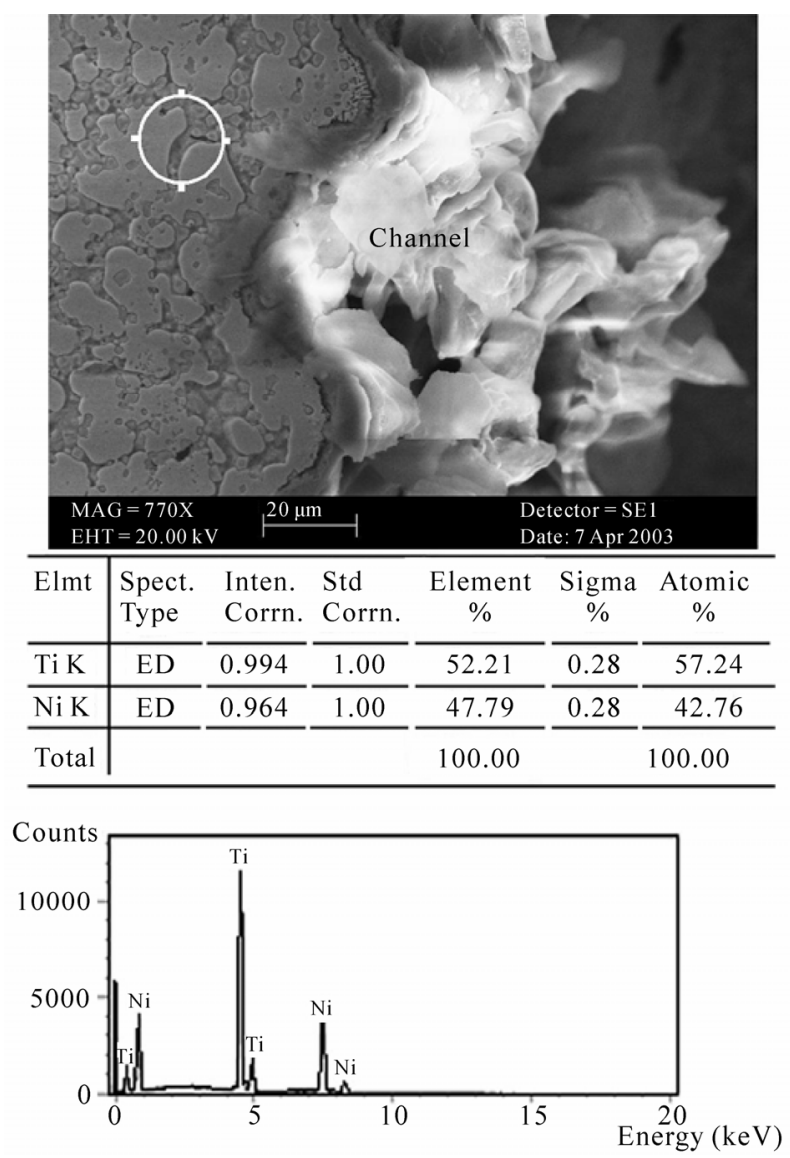

Figure 9. The results SEM-EDS of NiTi.



Figure 10. The schematic illustration of operation.

applying high-dose intravenous sodium penta-barbital. For the histological analyses, bone samples including the implants were taken from the dog and placed in a $10 \%$ formalin solution. 


\section{RESULTS}

\subsection{Atomic Absorption Analysis Results}

For atomic absorption analysis, 10-30-60 day blood serums were taken from the dog two times; before the operation (control) and after the operation. During these periods, the Ni level was determined by the blood tests since it is well known that $\mathrm{Ni}$ is very toxic in vivo. The tests were conducted using Atomic Absorption Spectrometer (ATI929) device in The Faculty of Science at Firat University, Department of Chemistry. Table 2 displays test results of atomic absorption analysis. As seen in Table 2, the results of the obtained data indicate that $\mathrm{Ni}$ was smaller than 1; that is to say Ni-Ti did not have a toxic effect on the subject in present form.

\subsection{Radiogram and Digitals-SEM Analysis}

The radiographic views of the tibia of the subject two months later after the placement are seen in $1 / 2$ and $1 / 4$ cross sections and Figure 11 illustrates radiograms from various durations on the tibia.

The test sample was divided into two and thus some part of the test sample was revealed. This appearance is presented in Figure 12. SEM images were taken from the regions marked as 1-2-3-4 and 4-5 in Figure 12. It is seen from images that each image was taken from different regions in Figure 12. As observed from these images, formation of a mechanical binding between the bone tissue and NiTi occurred and no pathological case was available at these points. Image 12-2 was taken from the channel on NiTi and a firm bone tissue formation is observed to have occurred on the tissue NiTi progressing through the channel. Likewise, the same situation is observed clearly in Figure 12(e).

SEM examinations revealed that bone tissue formation extended to the pores and the channels formed as a result of the resorption of NiTi in the implant in the direct proportion with 2-month time (Figure 12(d)). It was seen that periosteum and bone tissue were formed on the outer surface of the NiTi implant in the sample (Figures 12(a-d)). In this sample, apart from Havers channels and lamellar structure, formation of blood vessels is also seen from SEM images (Figures 12(a-d)). [16]

\subsection{Pathological Analysis}

At the end of the analysis, no pathological cases were found and also a formation having no pathological risk between bone tissue and implant material (Ni-Ti) was determined. The endochondral ossification and trabecular bone (arrow) between the bone tissue and the implant are distinguished in Figure 13. Hematoxylen eosin x20 (Figure 13).

\section{DISCUSSIONS}

The Ni-Ti used in the study was produced combining a bioinert metals (Ni-Ti) with a mechanical binding force $[11,15]$. Porous Ni-Ti alloy is a new type of material in terms of its pores' linear structure. As is seen, when $\mathrm{Ni}$-Ti powders are carefully mixed and ignited at suitable environment and temperatures, quite symmetrical structures are formed. When this alloy is used under in-vivo conditions with its homogenous distribution and open pore structure, the living tissue is provided to move through open channels on the sample. Because of their bioinert structures [11,12], it is possible for $\mathrm{Ni}-\mathrm{Ti}$ alloys to be used in in-vivo environment.

As a conclusion, since biomaterials are used on human body for a period of time or lifetime, properties of these materials have always been a subject of research conducted by many researchers. Today, one of the mostly-studied subjects by modern medicine and biomedical engineering is to select, create, or optimize appropriate materials used for treatment of diseases. It is necessary that the relationship among used materials, tissues carrying these materials, and the whole organism be as compatible and healthy as possible. Another necessity for these materials is to have properties to fulfill the function of the organ which they replaced with as implants. Therefore, considering the human body weight, the material to be used must resist without losing its coordination at $37^{\circ} \mathrm{C}$ and $7.25 \mathrm{pH}$ value, without presenting an adverse reaction to the tissue in contact, and without breaking and bending against mechanical forces. In addition, it is desirable that pores of samples produced as implants must be interconnected with each other from three dimensions, that's to say they must have open porous structures. Therefore, high open porosity lets not
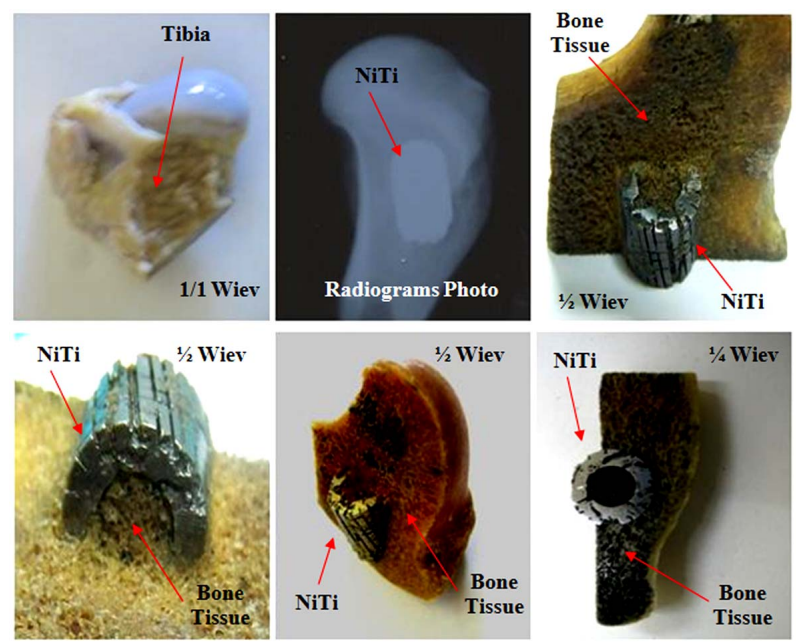

Figure 11. $1 / 2$ and $1 / 4$ cross sections and radiograms after the placement in the tibia of NiTi sample. 
Table 2. Atomic absorption analysis test result.

\begin{tabular}{ccccc}
\hline Results & Sample Volume (ml) & Oscillation & Absorb Ni & Sample Ni (mg/lt) \\
\hline Before Operation, Control & 0,76 & 1 & 4 \\
10 Day, Control & 0,95 & 1 & 3 & $<0,5$ \\
30 Day, Control & 0,86 & 1 & 6 \\
60 Day, Control & 0,79 & 1 & 7 \\
\hline
\end{tabular}


Figure 12. The picture SEM of tissue-NiTi implant at inside tibia.

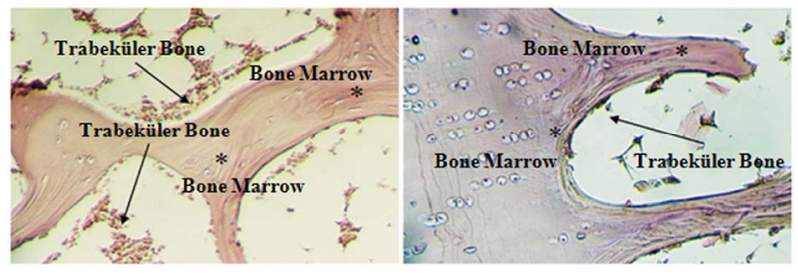

Figure 13. The picture of pathologicaly examination.

only the body fluid penetrate into the implant by making the tissue move easily in the implant but also soft or hard tissues penetrate into the implant material, and as a result, a stable interface occurs. In our study, it was observed that the tissue, in which this situation was provided, moved in the implant and no pathological cases occurred between the bone tissue and NiTi sample. In addition, the fact that $\mathrm{Ni}$ and $\mathrm{Ti}$ have low specific gravities supports our study in terms of mechanical aspect. In other words, the produced implant (NiTi) will be capable of resisting to mechanical forces without breaking and bending.

This study indicates that when compared to other known metallic materials of today, porous NiTi alloy is the most important alternative material to be used instead of natural bone. However, in order to reach a conclusive result this study should be examined with similar studies on different test subjects and in different periods, because researchers are required to make further investigations on these subjects.

The following study should focus on a hybrid biomaterial (Ni-Ti and hydroxyapatite) production combining the ignition mechanism and the sintering. Utilizing the resulted reaction temperature and the temperature output allows materials to be produced economically in powder metallurgy based Ni-Ti-Cu or other alloys.

The studies related to biomaterial should be on restructuring the natural tissues by using the capacity of body's renewing itself instead of replacing a healthy tissue with the damaged tissue. For this reason, the biomaterials to provide restructuring the natural tissues require to be improved.

\section{ACKNOWLEDGEMENTS}

In this study was supported by TUBITAK research council (Project No. 
TUBITAK 2002-K).

\section{REFERENCES}

[1] Gür, A.K. (2004) The producing of Ni-Ti alloys and investigation of In-Vivo biocompability, Master Thesis, Firat University, Elaziğ, Turkey.

[2] Edgerton, M. and Levine, M.J. (1993) Biocompatibility: Its future in prosthodontic research. Journal of Prosthetic Dentistry, 69, 406-415.

[3] Ayhan, H. (2002) Biomaterials. The Magazine Technical and Science, July 2002.

[4] Sarilmaz, F. (2003) The investigation of the usability of polymer-hydroxyapatite composits in orthopedy as a biomaterial, Master Thesis, Firat University, Elaziğ, Turkey.

[5] Park, J.B. (2000) Biomaterials. In: Bronzino, J.D., Ed., The Biomedical Engineering Handbook, 2nd Edition. 2 Volume Set. CRC Press LLC, Boca Raton, Section IV.

[6] Hench, L.L. and Ethridge, E.C. (1982).Biomaterials: An interfacial approach, Academic Press, New York.

[7] Jonn, B.P. and Young, K.K. (2000) Biomedical Enginering Handbook, Unit: 37 Metalic Biomaterials.

[8] Gür, A.K. and Taşkın, M. (2004) Metallic biomaterials and biocompability, DAUM, Firat University, Elaziğ, Turkey.

[9] Niinomi, M. (2002) Recent metalic materials for biomedical applications. Metalurgical and Materials Transactions A, 33, 477-486.

[10] Bogdanski, D., Köller, M., Müller, D.,Muhr, G., Bram, M., Buchkremer, P.H., Stöver D., Choi, J. and Epple, M. (2002) Easy assement of the biocompability of $\mathrm{Ni}-\mathrm{Ti}$ alloys by in-vitro cell culture experiments on a functionally graded Ni-Ni Ti-Ti Material. Biomaterials, 23, 4549-4555.

[11] Li, B.Y., Rong, L.J., Li, Y.Y. and Gjunter, V.E. (2000) A recent development in producing prous $\mathrm{Ni}-\mathrm{Ti}$ shape memory alloys, Intermetallics, 8, 881-884.

[12] Li, B.Y., Rong, L.J., Li, Y.Y. and Gjunter, V.E. (2000) Synthesis of prous Ni-Ti shape memory alloys by self-propagating high-temperature synthesis: Reaction mechanism and anisotropy in pore structure. Acta Materialia, 48, 3895-3904.

[13] Pakhomenko, J.S., Syrkashev, V.A. and Gjunter, V.E. (1996) Superplastic shape memory alloys materials and implants in medicine. Prosesesing of the Internotionals Conference Tomsk, Russia Resarch Institue of Medical Materials and Shape Memory Implants, 1996, 20.

[14] Orhan, N., Taskin, M., Gür, A.K. and Ünsaldi, E. (2003) The effect of igniting on according porous and channel direction produceded PM NiTinol alloys. Proceedings of the 3nd International Symposium on Advanced Technology, Ankara, University of Gazi, 2003, 71-77.

[15] Kaya, M., Orhan, N. and Kurt, B. (2009) Effect of solution treatment underload on microstructure and fabrication of porous NiTi shape memory alloy by self-propagating high temperature synthesis. Powder Metallurgy, 52, 36-41.

[16] Sarsilmaz, F., Orhan, N., Unsaldi, E., Durmus, A.S. and Colakoglu, N. (2007) A polyethylene-high proportion hydroxyapatite implant and its investigation in vivo. Acta of Bioengineering and Biomechanics, 9, 9-16. 